\title{
Radiometric fingerprinting of fluvial sediments in the Rhine-Meuse delta, the Netherlands - a feasibility test
}

\author{
K. Hebinck ${ }^{1}$, H. Middelkoop ${ }^{1,}{ }^{*}$, N. van Diepen ${ }^{1}$, E.R. van der Graaf $^{2}$ \& R.J. de Meijer $^{2}$
}

1 Dept. Physical Geography, Universiteit Utrecht, P.0. Box 80115, 3508 TC Utrecht, the Netherlands.

2 Nuclear Geophysics Division - Kernfysisch Versneller Instituut, University of Groningen, the Netherlands.

* Corresponding author. Email: h.middelkoop@geo.uu.nl

Manuscript received: April 2007; accepted: October 2007

\begin{abstract}
The deposits of the Rhine and, the Meuse in the Netherlands alternate in their delta in a complex way. This paper discusses a method to distinguish the deposits of the Rhine and the Meuse based on the differences in natural radioactivity of ${ }^{40} \mathrm{~K},{ }^{238} \mathrm{U}$ and ${ }^{232} \mathrm{Th}$, and the effect of the age of the deposits on the radiometric signal. In total, six channel belts of the Rhine and the Meuse were selected for sampling with an approximate age of about 2000, 4000 and $6000{ }^{14} \mathrm{C}$ years B.P. Of each channel belt 5 samples of different lithology were taken: clay (C), clay loam (CL), sandy clay loam (sCL), sandy loam (sL) and sand (S). All samples were analysed on organic matter content, grain size, geochemistry and radioactivity of the radionuclides ${ }^{40} \mathrm{~K},{ }^{238} \mathrm{U}$ and ${ }^{232} \mathrm{Th}$. The radioactivity of the sample is mainly influenced by the grain size of the sample. Therefore, this signal is divided in partial radioactivities for three grain size fractions - clay ( $<16 \mu \mathrm{m})$, silt (16 - $63 \mu \mathrm{m})$ and sand (>63 $\mu \mathrm{m})-$ to make the radiometric fingerprint, which is independent of the grain size of the sample. These fingerprints show a difference between the Rhine and the Meuse. Additionally, the radiometric signal strongly depends on the age of the deposits. Remarkably, this trend with age is opposite in the deposits of the Rhine and the Meuse and opposite in the clay and silt fraction. Because the radiometric differences between the samples seem more distinct than the geochemical differences, the radiometric fingerprints are more suitable to distinguish the deposits of the Rhine and the Meuse. A method is presented to derive the contribution of the Rhine and the Meuse in a deposit of unknown origin, assuming that the radiometric fingerprints found are consistent and valid for the Rhine-Meuse delta. To distinguish the deposits of the Rhine and the Meuse, both the grain size composition and the age of the deposits have to be known.
\end{abstract}

Keywords: sediment provenance, radiometric fingerprinting, Rhine-Meuse delta, fluvial sediments, natural radioactivity

\section{Introduction}

The palaeogeographic development and the alluvial architecture of the Holocene Rhine-Meuse Delta in the Netherlands have been studied extensively (e.g., Berendsen \& Stouthamer, 2001). The different channel belts of the Rhine and the Meuse in their common delta have been mapped in detail, using over 200,000 corings and more than $1500{ }^{14} \mathrm{C}$ dates (Berendsen \& Stouthamer, 2001), revealing the complex development of both rivers in the delta. One of the key issues in the palaeogeographic reconstruction is to determine whether deposits originate from either the Rhine or the Meuse River. This is essential to assess changes of sediment supply the upstream river basins, e.g. due to climate change or human impact, and their effects on sediment accumulation rates or channel change in the delta (Stouthamer, 2001). However, over large parts of the delta, the deposits of the Rhine and the Meuse alternate both laterally and vertically in a complicated way. Channel belt deposits from the Rhine and the Meuse can generally be distinguished by e.g. their heavy mineral content (Berendsen, 1996) or by detailed mapping of these channel belts. However, these methods fail for floodplain fines. Particularly when floodbasins are bordered by channel belts from both rivers, only a rough estimate can be made for the relative proportion of floodplain fines supplied by either the Rhine or Meuse Rivers. 
A promising approach that helps tracing sediment provenance was introduced by Venema et al. $(1998,1999)$ and Van Wijngaarden et al. (2002a and b). In these studies differences were measured between the activity concentrations of ${ }^{40} \mathrm{~K}$, ${ }^{238} \mathrm{U}$ and ${ }^{232} \mathrm{Th}$ in mud and sand deposits in order to conduct sand-mud mapping of the bottom of the Haringvliet and Hollandsch Diep in the Rhine-Meuse estuary, the Netherlands. Additionally, they found a small difference in radioactivity between the Rhine and the Meuse in the recent clay deposits. This indicated the potential of using radiometric fingerprinting to determine whether Holocene deposits originate from the Rhine or Meuse River.

Over the past decennia various fingerprinting techniques have been employed to determine the source areas of sediments in river basins (Collins \& Walling, 2002, 2004). The fingerprinting approach is founded on 2 key stages: 1) source discrimination, i.e. the ability to discriminate from the fingerprint that there have been different source areas of the deposits, and 2) source ascription, i.e. the ability to assign these fingerprints to specific source areas. Potential fluvial sediment sources may involve source types (hillslopes versus river channels, surface versus subsurface) or spatial sources (c.q. tributary subcatchments or geological units). Traditional approaches to sediment source assessment based on mapping areas of erosion and sediment routing through the river channel are heavily constrained by numerous operational and logistical problems and the costs involved. Such approaches cannot be used to reconstruct the historical sources of sediment deposits. This is a key strength of the fingerprinting approach in that it can be readily used to examine historical sediment sources. The fingerprinting approach is increasingly based on the use of composite fingerprints. Composite fingerprints comprise constituents responding to differing environmental controls and which in combination thereby provide more robust source discrimination. The search for a single diagnostic property has proved elusive over the past 20 years and the use of a single property is prone to the confounding effects of spurious sediment-source matches (Collins \& Walling, 2004).

Mineralogic composition of coarse sediment fractions, relative contents of different clay minerals in the finer fractions, or chemical composition of fluvial deposits have been related to different source areas, or to varying climate conditions in the upstream basins (e.g., Johnson \& Kelly, 1984; Garrad \& Hey, 1989; Phillips, 1992; Collins et al., 1997; Tebbens, 1999; Collins \& Walling, 2002; Gingele \& de Decker, 2003). These mineralogic fingerprints largely reflect differences in lithology within the upstream basins and varying weathering and erosion rates over time. Likewise, magnetic fingerprinting of suspended sediments has been used to identify different source areas (e.g., Oldfield et al., 1979; Walden et al., 1997; Slattery et al., 2000). Furthermore, maninduced contamination of sediments has been used to determine sediment sources in contaminated catchments (e.g.
Lewin \& Wolfenden, 1978), and to reconstruct long-term overbank sedimentation rates (e.g., Hakstege et al., 1993; Middelkoop, 2000). The use of radiometric characteristics to determine source areas of suspended sediments is reported by e.g. Loughran et al. (1982), Peart \& Walling (1986), Walling \& Woodward (1992), Collins et al. (1997) and Porto et al. (2003). These studies used fall-out radionuclides, such as ${ }^{137} \mathrm{Cs}$ and ${ }^{210} \mathrm{~Pb}$ as a tracer to distinguish sediment derived from surface erosion with high excess-activities from sediment sources consisting of older deposits. Using natural radionuclides ${ }^{40} \mathrm{~K},{ }^{238} \mathrm{U}$ and ${ }^{232}$ Th as tracers, De Meijer et al. (1990) and De Meijer \& Donoghue (1995) investigated transport of marine sediments in the Wadden Sea and identified different rivers (Rhine, ElbeWeser-Ems) and glacial deposits as sediment sources. Application of these natural radionuclides in fluvial sediments, however, remains to be explored.

The objective of our study was to evaluate whether radiometric fingerprinting using the natural radio-isotopes ${ }^{40} \mathrm{~K},{ }^{238} \mathrm{U}$ and ${ }^{232} \mathrm{Th}$ can be applied to determine if floodbasin deposits in the Holocene Rhine Meuse delta origin from the Rhine or Meuse River. For this purpose we analysed to what extent the radiometric signal of Rhine and Meuse sediments is determined by their origin, the grain size of the sediment and the age of the deposits. Furthermore, we evaluated whether using the radiometric signal of the sediments would provide a more robust source discrimination than the sediment geochemistry.

\section{Methods}

The analyses were carried out by determining the radiometric signal of sediment samples of different lithology, taken from selected dated channel belts of the lower Rhine and Meuse, of different known age. The sample sites were located in the eastern part of the delta where the deposits of the Rhine and the Meuse are separated by a number of eolian dunes, such that the source area (Rhine or Meuse) of the sediment is known. This is not the case in the western part of the delta, where the deposits of the Rhine and the Meuse are mixed. For the analysis of the radiometric characteristics we selected six channel belts for sampling; three from the Rhine and three from the Meuse (Fig. 1, Table 1). The three channel belts of both rivers have an approximate age of about 6000, 4000 and $2000{ }^{14} \mathrm{C}$ years B.P. (Berendsen \& Stouthamer, 2002), which allowed determining whether the radiometric signal has changed with time during the Holocene. For the investigation of the effect of the grain size of the sediment on the radioactivity, five samples of different lithology were taken at all locations. The samples included: clay (C), clay loam (CL), sandy clay loam (sCL), sandy loam (sL) and sand (S) (cf. Schoeneberger et al., 2002). In each channel belt, detailed lithological cross sections were made to select the sample locations. An example of the cross sections with sample locations at the Echteld site is shown in Fig. 2. Sand was sampled from the channel deposits 
Fig. 1. Location of the sample sites. Map after Berendsen \& Stouthamer (2001).

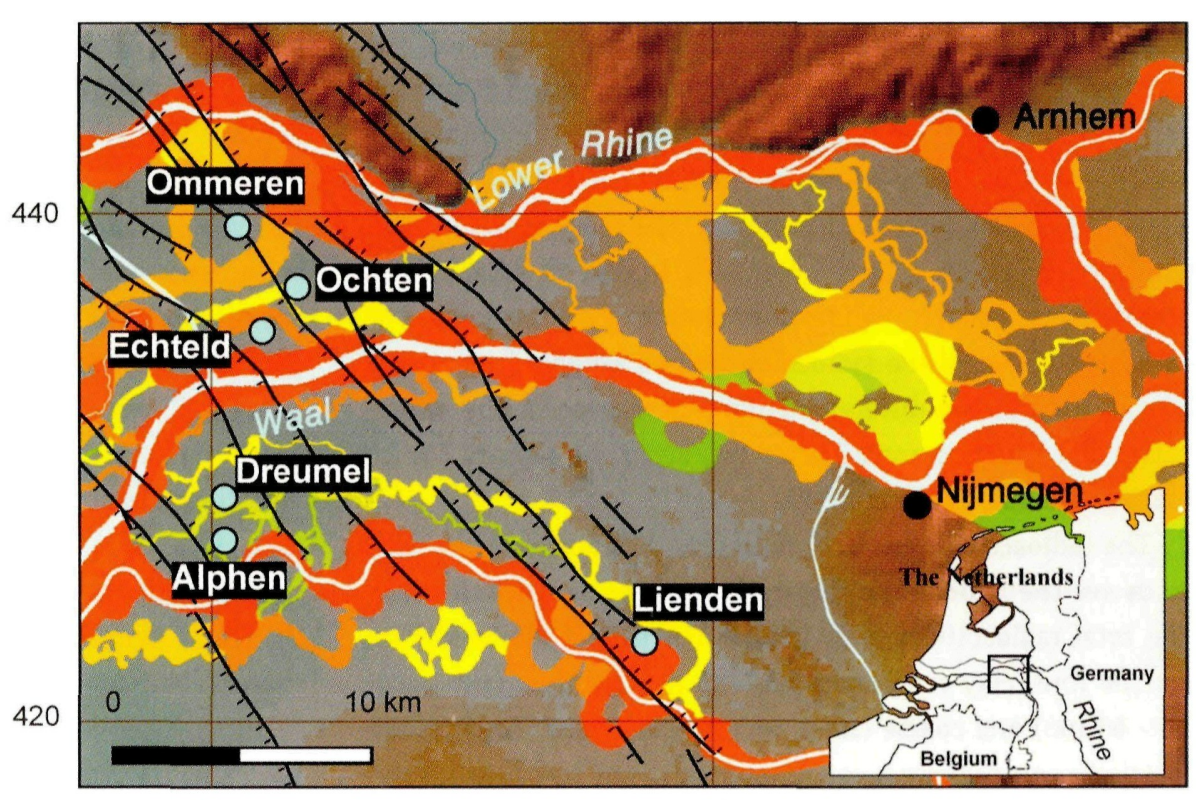

160
180 of the channel belt, clay loam, sandy clay loam and sandy loam deposits were sampled in the overbank deposits and the clay in the floodbasin. The sand samples were taken with a Van Der Staay suction corer, while the other samples with an Edelman hand auger. Per sample a volume of about 1 litre sediment was taken in several corings within a depth interval of maximum $10 \mathrm{~cm}$.

The samples were analysed in the laboratory for determination of the grain size distribution, organic matter content, geochemistry and radioactivity. The grain size distribution was determined by laser diffraction with a Coulter LS after removal of the organic matter with $30 \%$ hydrogen peroxide and removal of $\mathrm{CaCO}_{3}$ with $30 \%$ hydrochloric acid. The organic matter content was determined by loss on ignition at $550^{\circ} \mathrm{C}$ for four hours. This was done because the organic matter content may influence the radioactivity of the sample (Venema et al., 1998). The geochemistry was measured with X-ray fluorescence spectroscopy (XRF). The geochemistry was analysed on 11 main elements $\left(\mathrm{SiO}_{2}, \mathrm{Al}_{2} \mathrm{O}_{3}, \mathrm{TiO}_{2}, \mathrm{Fe}_{2} \mathrm{O}_{3}, \mathrm{MnO}, \mathrm{CaO}, \mathrm{MgO}, \mathrm{Na}_{2} \mathrm{O}, \mathrm{K}_{2} \mathrm{O}\right.$, $\mathrm{P}_{2} \mathrm{O}_{5}$ en $\mathrm{S}$ ) and 20 trace elements ( $\mathrm{As}, \mathrm{Cu}, \mathrm{Pb}, \mathrm{Zn}, \mathrm{Ni}, \mathrm{Cr}, \mathrm{V}, \mathrm{Sn}$, $\mathrm{Sr}, \mathrm{Ba}, \mathrm{Rb}, \mathrm{Ga}, \mathrm{Zr}, \mathrm{Nb}, \mathrm{Y}, \mathrm{Sc}, \mathrm{La}, \mathrm{Nd}$, Th and U).

Table 1. Selected sample locations with corresponding age of the channel belts

\begin{tabular}{lll}
\hline Sample location & Active phase $\left({ }^{14} \mathrm{C}\right.$ yr $\left.\mathrm{BP}\right)$ \\
\hline Rhine & Echteld & 2770 to $1901^{*}$ \\
& 0chten & 4610 to $3290^{*}$ \\
Ommeren & About $6000^{* *}$ \\
Meuse & Lienden & 3000 to $2000^{*}$ \\
& Dreumel & 4370 to $3765^{*}$ \\
& Alphen & About $6000^{* *}$ \\
\hline
\end{tabular}

* Berendsen and Stouthamer (2001); ** Cohen (2003)
The measurements of the radioactivity of the different elements were carried out in the laboratory of the Nuclear Geophysics Division at the Kernfysisch Versneller Instituut (KVI) in Groningen. The procedure for measurement and analysis was conform the standards of NEN 5623 (NEN, 2000). The radioactivity of the samples $\left(\mathrm{Bq} \mathrm{kg}^{-1}\right)$ was measured using various gamma-rays emitted by radionuclides from the decay series of ${ }^{238} \mathrm{U}$ and ${ }^{232} \mathrm{Th}$ and the $1461 \mathrm{keV}$ gamma line of ${ }^{40} \mathrm{~K}$ (De Meijer, 1998). The dried and weighted samples of 1 litre were placed in a Marinelli beaker on a hyper-pure germanium detector (HPGe) for 24 hours. The detector and the sample were surrounded by a lead shielding of $10 \mathrm{~cm}$ to reduce the natural background $\gamma$-radiation. The gamma-radiation was collected as spectra in which the specific activities were derived by the

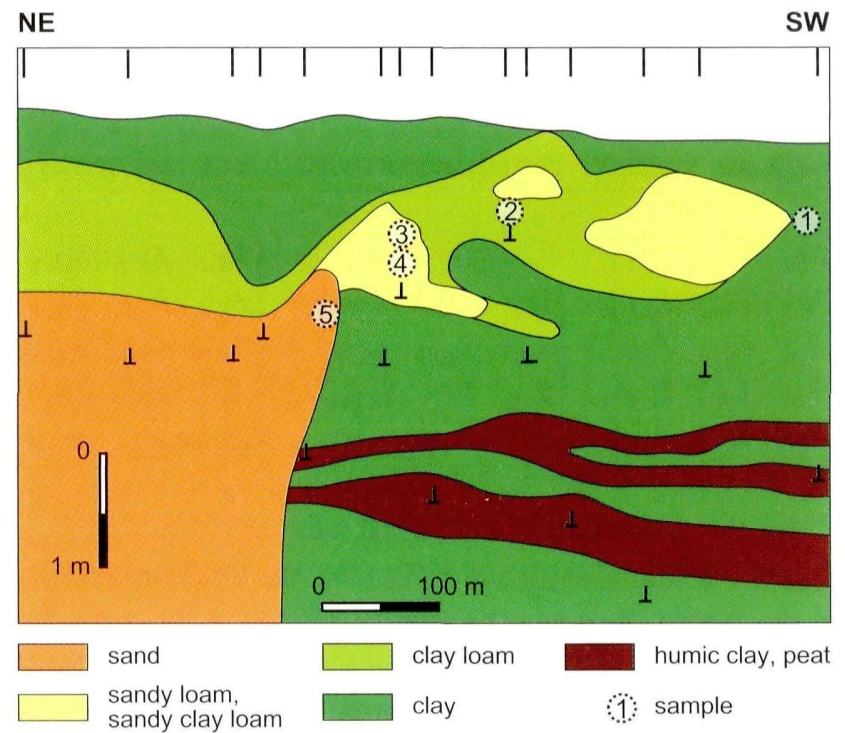

Fig. 2. Detailed cross section of the channel belt at Echteld. Numbers indicate sample locations: 1 = clay, 2 = clay loam, 3 = sandy clay loam, $4=$ sandy loam, 5 = sand. 
intensity of the peaks (De Meijer, 1998). In the samples, the secular equilibrium of the decay-series is initially not present for uranium, because radon gas $\left({ }^{222} \mathrm{Rn}\right)$, an intermediate member of the decay-series of uranium, may have (partly) escaped from the sediment. Therefore, the samples were stored for three weeks in a sealed Marinelli beaker to establish an approximate secular equilibrium before measurement. The measured values of the radioactivity are a weighted average of the activity of the different daughter-isotopes in the decayseries and have a standard error (sd/mean) of about $1.5 \%$ for ${ }^{40} \mathrm{~K}$ and $2 \%$ for ${ }^{238} \mathrm{U}$ and ${ }^{232} \mathrm{Th}$.

The radioactivity and the grain size distribution were used to derive the radiometric fingerprints of the samples in which the total radioactivity is divided in the partial radioactivities for the fine (clay-sized material, $<16 \mu \mathrm{m}$ ) medium (silt-sized, $16-63 \mu \mathrm{m}$ ) and coarse (sand, $>63 \mu \mathrm{m}$ ) fractions. These radiometric fingerprints were constructed with the so-called inverse matrix method (Van Wijngaarden et al., 2000). This method is based on the assumption that the total radioactivity $(A)$ of an isotope $X$ in sample $\mathrm{i}$ is the sum of the partial radioactivities $\left(S\right.$, in $\left.\mathrm{Bq} \mathrm{kg}^{-1}\right)$ of the fine $(f)$, medium $(m)$ and coarse $(c)$ grain size fraction $\left(F\right.$, between 0 and 1 , with $\left.F_{f, i}+F_{m, i}+F_{c, i}=1\right)$, according to the following equation

$$
A_{X, i}=F_{f, i} \cdot S_{f, X}+F_{m, i} \cdot S_{m, X}+F_{c, i} \cdot S_{c, X}
$$

In this model it is assumed that the partial radioactivities (S) are characteristic for the sediment source (and age), and thus constitute the radiometric fingerprint. The partial activities of the three grain size fractions are assumed to be the same in all five samples taken from the same channel belt. So, for the total activities of ${ }^{40} \mathrm{~K}(K),{ }^{238} \mathrm{U}(U)$ and ${ }^{232} \mathrm{Th}(\mathrm{Th})$ in the five different samples taken per channel belt, this results in 15 equations per channel belt. These 15 equations form the following matrix equation, where the numbers refer to the samples:

Grain size matrix Partial radioactivity Total radioactivity

$$
\left|\begin{array}{lll}
F_{f, 1} & F_{m, 1} & F_{c, 1} \\
F_{f, 2} & F_{m, 2} & F_{c, 2} \\
F_{f, 3} & F_{m, 3} & F_{c, 3} \\
F_{f, 4} & F_{m, 4} & F_{c, 4} \\
F_{f, 5} & F_{m, 5} & F_{c, 5}
\end{array}\right| \cdot\left|\begin{array}{lll}
S_{f, K} & S_{f, U} & S_{f, T h} \\
S_{m, K} & S_{m, U} & S_{m, T h} \\
S_{c, K} & S_{c, U} & S_{c, T h}
\end{array}\right|=\left|\begin{array}{lll}
A_{K, 1} & A_{U, 1} & A_{T h, 1} \\
A_{K, 2} & A_{U, 2} & A_{T h, 2} \\
A_{K, 3} & A_{U, 3} & A_{T h, 3} \\
A_{K, 4} & A_{U, 4} & A_{T h, 4} \\
A_{K, 5} & A_{U, 5} & A_{T h, 5}
\end{array}\right|
$$

For the calculation of the partial radioactivities $\left(S_{f, X} ; S_{m, X}\right.$; $\left.S_{C, X}\right)$ of ${ }^{40} \mathrm{~K}(K),{ }^{238} \mathrm{U}(U)$ and ${ }^{232} \mathrm{Th}(\mathrm{Th})$, the total radioactivity in the sample $\left(A_{X, i}\right)$ and the relative weights of the grain size fractions $\left(F_{f, i} ; F_{m, i} ; F_{c, i}\right)$ were determined for each sample. Using these, the matrix of unknown partial radioactivities (fingerprint) was calculated. Since the system is over-determined (five samples to calculate three partial radioactivities) the partial radioactivities were determined using a least squares fit. The resulting partial radioactivity matrix is thus the radiometric fingerprint of the sampled channel belt. The model requires that the same fraction boundaries have to be used for all different samples to calculate the partial radioactivities. For this research it was attempted to determine fraction boundaries that might represent different modes of transportation and deposition of the sediment (i.e. wash load, suspension/saltation, rolling bed load), which would then reflect a 'natural' way of sediment sorting. However, there might be other factors that have affected the grain sizes of the investigated samples. The fingerprints of partial radioactivities $\left(S_{f, X} ; S_{m, X} ; S_{c, X}\right)$ of the different channel belts were finally compared to identify the differences between the Rhine and the Meuse deposits, and to determine whether they depend on channel belt age.

\section{Uncertainty analysis}

Uncertainty in the radiometric fingerprints originates from a number of sources, including the natural variability of fingerprint properties characterising individual sources (Motha et al., 2004; Collins \& Walling, 2007). To estimate this uncertainty we had only a limited number of samples available: for each time slice and source, we investigated one channel belt, from each of which we took five samples. This did not allow determining the variability in fingerprint among different channel belts of the same age and source. Alternatively, we estimated the uncertainty obtained in the fingerprint based on each set of 5 samples, associated with uncertainties in the grain size and radiometric measurements. This was done as follows: For each radionuclide $X$ in the fingerprints the evaluation criterion $J_{X}(S)$ was determined that compares the measured bulk radio activities $A_{X, \text { meas, } i}$ in the 5 samples $i$ with the calculated total activities $A_{X, \text { calc, }}$ obtained by multiplying the partial radioactivities $\left(S_{f, X}, S_{m, X}, S_{c, X}\right)$ with the grain size fractions $\left(F_{f, i} ; F_{m, i} ; F_{c, i}\right)$ as in eq. $1 J_{X}(S)$ was calculated as:

$$
J_{X}(S)=\sum_{i=1}^{5}\left(A_{X, \text { calc }, i}-A_{X, \text { meas }, i}\right)^{2}
$$

The fingerprints derived from the samples are those partial radioactivities $S_{f, X}, S_{m, X}, S_{c, X}$ for which the $J_{X}(S)$ has the lowest value. Due to measurement uncertainties of the grain size fractions and activities $A_{X, \text { meas, } i}$ in the bulk samples, there is uncertainty in the estimates of partial radioactivities. To quantify this uncertainty in the fingerprints, the values of the partial radioactivities $S_{f, X}, S_{m, X}$ and $S_{c, X}$ were varied between 0.2 - 2 times their value, with factor 0.2 increments, determined from the matrix equation. For each combination of varying $S_{f, X}$, $S_{m, X}$ and $S_{c, X}$, the resulting $A_{X, \text { calc, } i}$ and $J_{X}(S)$ were calculated. Subsequently, the sets of $S_{f, X}, S_{m, X}$, and $S_{c, X}$ were arranged according to increasing $J_{X}(S)$. Given the standard errors in the measurements of the radionuclide activities $\left(1.5 \%\right.$ for ${ }^{40} \mathrm{~K}$ and $2 \%$ for ${ }^{238} \mathrm{U}$ and ${ }^{232} \mathrm{Th}$ ), and an estimated error of $5 \%$ in the 
grain size fractions, an extra variance equal to $50 \%$ of $J_{X}(S)$ was added to the lowest value of $J_{X}(S)$ that is associated with the best set of partial radioactivities $S_{f, X}, S_{m, X}$ and $S_{c, X}$, This implies that all sets of partial radioactivities $S_{f, X}, S_{m, X}, S_{c, X}$ that yielded a $J_{X}(S)$ below this threshold were considered equally eligible to predict $A_{X, \text { calc, }}$. The uncertainty in the fingerprint was then determined as the standard deviations of the partial radioactivities $S_{f, X}, S_{m, X}$, and $S_{c, X}$ for which $J_{X}(S)$ was below the threshold. In a similar way, the uncertainties in the chemical fingerprints were determined, based on a $2 \%$ standard deviation in the chemical measurments.

\section{Results}

\section{Sediment characteristics}

The organic matter content in the samples varied from $0.5 \%$ in the sand samples to 4 to $11 \%$ in the clay samples with no large differences between the sampled channel belts. Therefore the organic matter had no influence on the radioactivity of the samples. The grain size distribution showed three different grain size fractions in each channel belt, but the boundaries between these fractions differ per sample (Fig. 3). Apparently, it is not possible to identify equal grain size fractions in the 30 samples, reflecting deposition mechanisms of the sediment. Therefore, standard fractions of clay-sized material $(<16 \mu \mathrm{m})$, silt $(16-63 \mu \mathrm{m})$ and sand $(>63 \mu \mathrm{m})$ were used as fine, medium and coarse fractions, of which the relative weights were used in the grain size matrix to calculate the partial radioactivity. The median grain size in the samples varied from about $9 \mu \mathrm{m}$ for the clay samples (C) to about $400 \mu \mathrm{m}$ for the sand samples (S).

The geochemistry shows some differences among the samples. The contents of the main components $\mathrm{SiO}_{2}, \mathrm{Al}_{2} \mathrm{O}_{3}$, $\mathrm{TiO}_{2}$ and $\mathrm{Fe}_{2} \mathrm{O}_{3}$ are mainly determined by the grain size of the sample, as shown in Fig. 4 for $\mathrm{Al}_{2} \mathrm{O}_{3}$. The contents of other elements ( $\mathrm{MgO}, \mathrm{CaO}, \mathrm{Na}_{2} \mathrm{O}$ and $\mathrm{P}_{2} \mathrm{O}_{5}$ ) also differ between the Rhine and the Meuse as shown in Fig. 4 for $\mathrm{Mg0}$. The content of the trace elements in the samples is mainly dependent on the grain size, where it is higher in the smaller grain size, such as e.g. for Ni (Fig. 4). Besides that, the elements Zn (Fig. 4), $\mathrm{Cr}, \mathrm{V}$ and Sr show higher concentrations in the Meuse sediments than in the Rhine sediments. The measured concentrations are

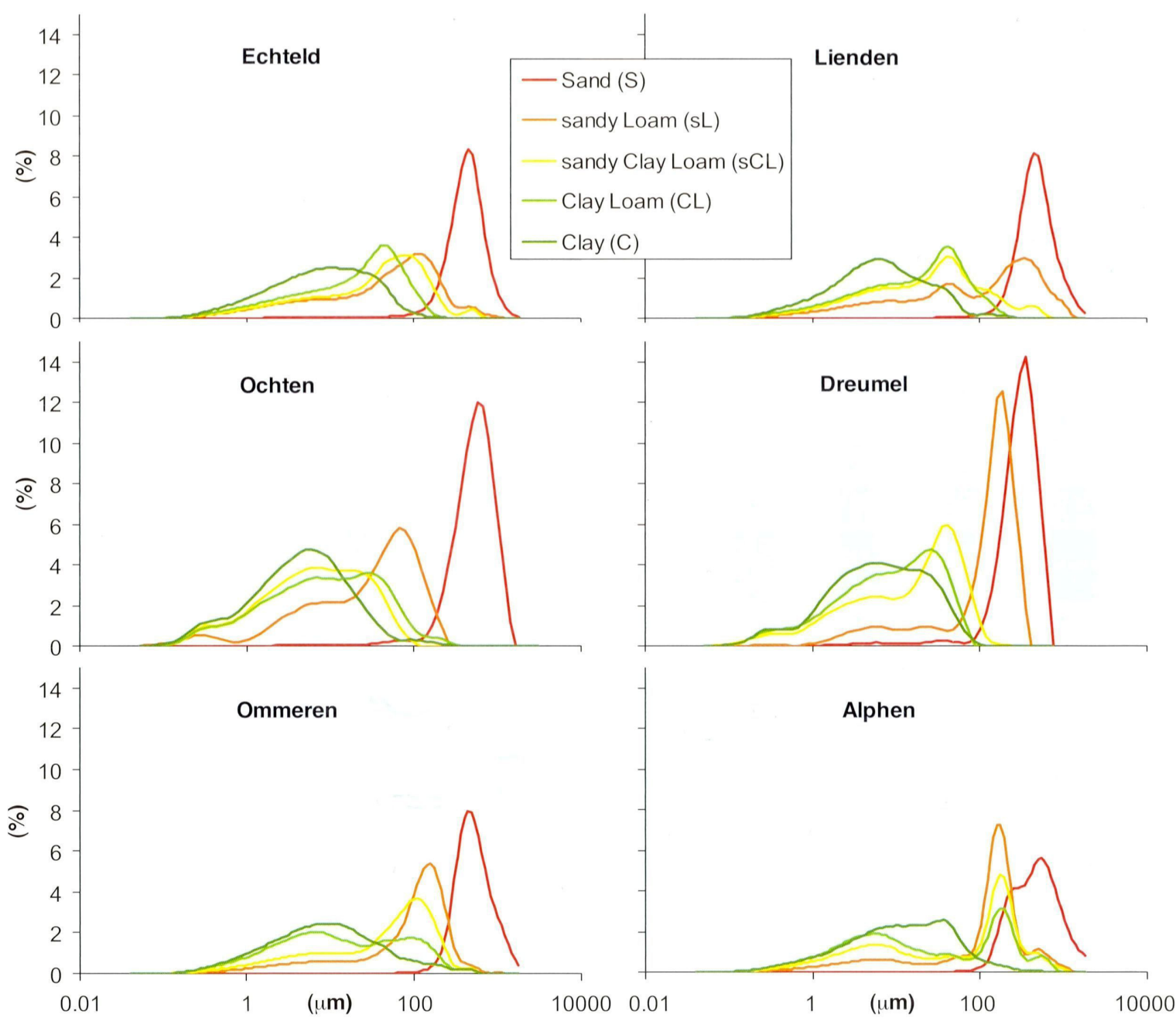

Fig. 3. Differential grain size distribution of the samples at the six sample locations (left: Rhine, right: Meuse; top: youngest, bottom: oldest). 

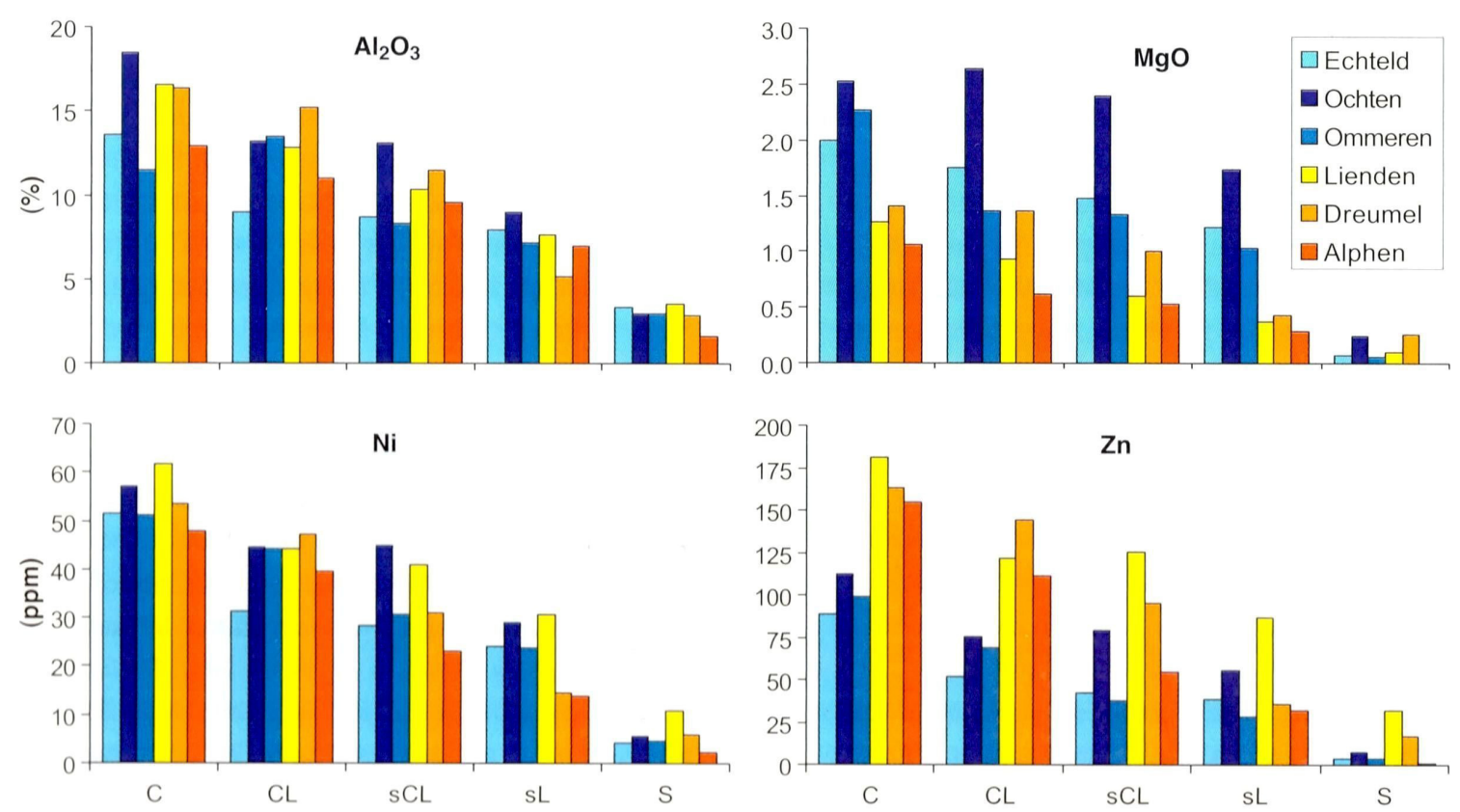

Fig. 4. Concentration of the geochemical components $\mathrm{Al}_{2} \mathrm{O}_{3}, \mathrm{MgO}$, Ni and $\mathrm{Zn}$ at the six sample locations for clay (C), clay loam (CL), sandy clay loam (sCL), sandy loam (sL) and sand (S) (blue bars: Rhine; yellow-red bars: Meuse).

comparable with concentrations in the Rhine-Meuse delta earlier found by Hakstege et al. (1993), indicating that this measured geochemistry is representative for the deposits of the Rhine and the Meuse throughout the delta. Differences in geochemistry with the age of the deposits in the Meuse were also found by Tebbens (1999).

The measured average radioactivities of ${ }^{40} \mathrm{~K},{ }^{232} \mathrm{Th}$ and ${ }^{238} \mathrm{U}$ in the samples show that the total radioactivity primarily depends on the grain size of the sample (Fig. 5). The clay samples have a higher total radioactivity than the sandy samples. The activity of ${ }^{232} \mathrm{Th}$ and ${ }^{238} \mathrm{U}$ is comparable, but the activity of ${ }^{40} \mathrm{~K}$ is about ten times higher. In this total radiometric signal no difference can be recognised between the Rhine and the Meuse, neither between deposits of different age. Therefore, to investigate the influence of the source area and the age of the deposits on the radioactive signal in the samples, this signal was made independent of the grain size using the partial activities.

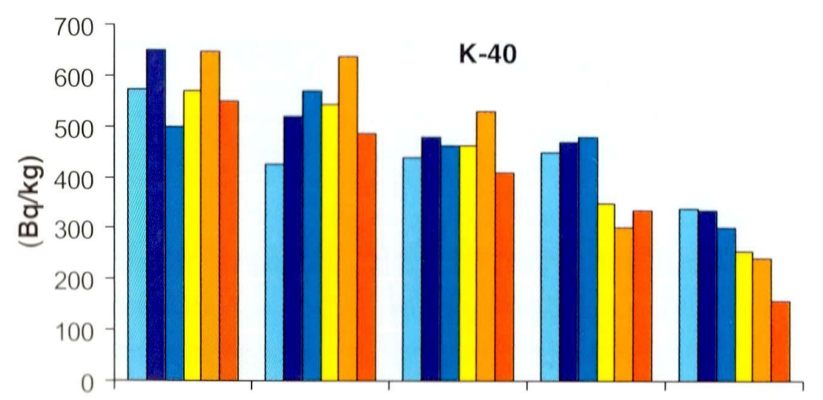

\section{$\square$ Echteld \\ - Ochten \\ - Ommeren \\ $\square$ Lienden \\ $\square$ Dreumel \\ alphen}


Fig. 5. Totol radioactivity of ${ }^{40} \mathrm{~K},{ }^{238} \mathrm{U}$ and ${ }^{232} \mathrm{Th}$ at the six sample locations for clay (C), clay loam (CL), sandy clay loam (sCL), sandy loam (sL) and sand (S) (blue bars: Rhine; yellow-red bars: Meuse). 


\section{Radiometric fingerprints}

The partial radioactivities of the grain size fractions calculated using the inverse matrix method from the percentages of the grain size fractions and the average total radioactivity of the samples from the Rhine and the Meuse deposits are shown in Table 2 and Fig. 6. It is apparent that there is a radiometric difference between the Rhine and the Meuse, now that the differences in sample grain size have been eliminated. Moreover, there seems to be a trend in the radioactivity with the age of the deposits. This trend is visible in the partial radioactivity of all three elements, ${ }^{40} \mathrm{~K},{ }^{238} \mathrm{U}$ and ${ }^{232} \mathrm{Th}$ (Fig. 7). The activities of ${ }^{40} \mathrm{~K}$ for the present-day situation were derived from the activities in suspended sediment of the Rhine and Meuse Rivers (data Ministry of Traffic, Public Works and Water Management, www.waterbase.nl). The sand fraction in not shown in Fig. 7, because the radioactivity in this fraction is low and no large differences appear between the Rhine and the Meuse sands. This is in accordance with Venema et al. (1998) who also found little radioactive material in the coarse sediment fractions. It is striking that the difference between the Rhine and the Meuse in the oldest deposits (6000 yr BP) is opposite to the difference in the youngest deposits. Remarkably, these differences in the clay fraction are opposite to those shown for the silt fraction. Furthermore, Figure 7 suggests that deposits of about $4000{ }^{14} \mathrm{C}$ years BP show only small differences in radiometry between the Rhine and the Meuse.

\section{Uncertainty analysis}

Figure $8 \mathrm{a}$ shows the values of the evaluation criterion $J_{K}(S)$ obtained for ${ }^{40} \mathrm{~K}$ in the Echteld (Rhine) sample set, arranged
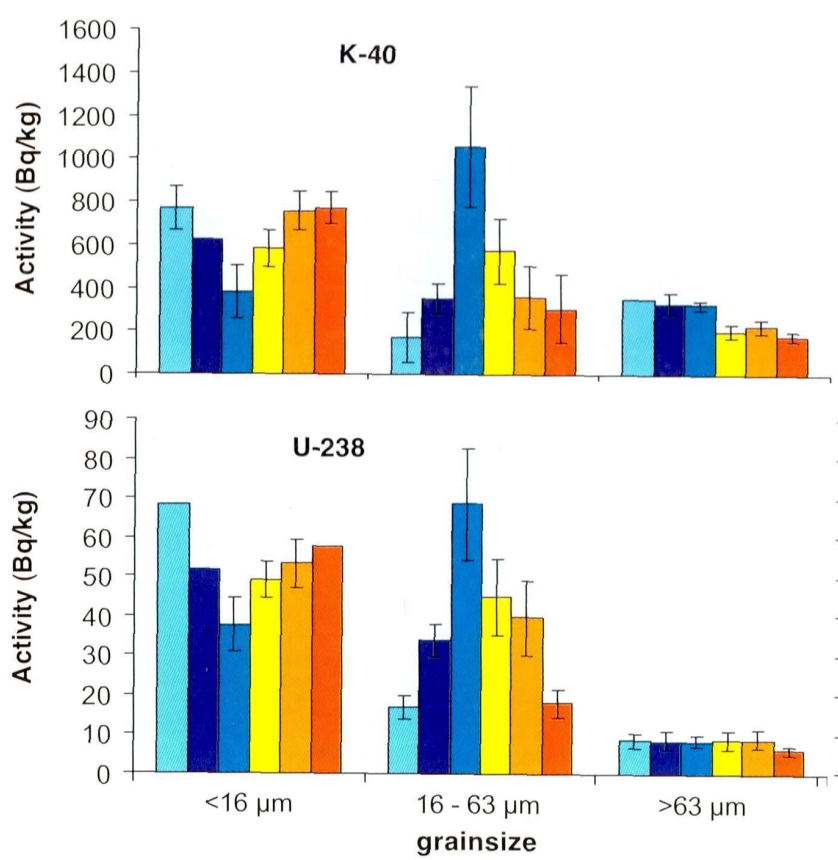

Table 2. Partial radioactivity of ${ }^{40} \mathrm{~K},{ }^{238} \mathrm{U}$ and ${ }^{232} \mathrm{Th}$ for the different sample sites. Average values (Avg.) and standard deviations (Sd.).

\begin{tabular}{|c|c|c|c|c|c|c|c|c|}
\hline \multirow[t]{2}{*}{ Location } & \multirow[t]{2}{*}{$\begin{array}{l}\text { Fraction } \\
(\mu \mathrm{m})\end{array}$} & \multicolumn{2}{|c|}{$\begin{array}{l}\mathrm{K}-40 \\
(\mathrm{~Bq} / \mathrm{kg})\end{array}$} & \multicolumn{2}{|c|}{$\frac{\mathrm{U}-238}{(\mathrm{~Bq} / \mathrm{kg})}$} & \multicolumn{3}{|c|}{$\begin{array}{l}\text { Th-232 } \\
(\mathrm{Bq} / \mathrm{kg})\end{array}$} \\
\hline & & Avg. & Sd. & Avg. & Sd. & Avg. & & Sd. \\
\hline \multicolumn{9}{|l|}{ Rhine } \\
\hline \multirow[t]{3}{*}{ Echteld } & $<16$ & 770 & \pm 103 & 68.3 & \pm 0.0 & $58.8=$ & \pm & 5.5 \\
\hline & $16-63$ & 171 & \pm 114 & 16.8 & \pm 2.9 & $20.1=$ & $\pm \varepsilon$ & 8.1 \\
\hline & $>63$ & 346 & $\pm \quad 0.0$ & 8.7 & \pm 1.8 & $9.6=$ & \pm 1 & 1.8 \\
\hline \multirow[t]{3}{*}{ 0chten } & $<16$ & 621 & $\pm \quad 0.0$ & 51.9 & \pm 0.0 & $50.4=$ & \pm & 0.0 \\
\hline & $16-63$ & 351 & \pm 69 & 34.1 & \pm 4.2 & $31.7=$ & \pm & 4.1 \\
\hline & $>63$ & 330 & \pm 51 & 8.6 & \pm 2.2 & $9.2=$ & \pm & 2.1 \\
\hline \multirow[t]{3}{*}{ 0mmeren } & $<16$ & 383 & \pm 124 & 37.8 & \pm 6.6 & $38.0=$ & \pm & 6.7 \\
\hline & $16-63$ & 1056 & \pm 278 & 68.7 & \pm 14.2 & $64.0=$ & & 13.2 \\
\hline & $>63$ & 323 & $\pm \quad 20$ & 8.6 & \pm 1.5 & $9.6=$ & \pm & 1.7 \\
\hline \multicolumn{9}{|l|}{ Meuse } \\
\hline \multirow[t]{3}{*}{ Lienden } & $<16$ & 584 & \pm 86 & 49.3 & \pm 4.6 & $51.4=$ & \pm & 3.3 \\
\hline & $16-63$ & 573 & \pm 151 & 45 & \pm 9.9 & $45.4=$ & \pm & 8.4 \\
\hline & $>63$ & 203 & \pm 33 & 8.7 & \pm 2.4 & $8.5=$ & \pm & 2.6 \\
\hline \multirow[t]{3}{*}{ Dreumel } & $<16$ & 756 & \pm 87 & 53.3 & \pm 6.0 & $56.8=$ & \pm & 5.3 \\
\hline & $16-63$ & 356 & \pm 150 & 39.7 & \pm 9.5 & $41.1 \pm$ & \pm & 8.9 \\
\hline & $>63$ & 227 & $\pm \quad 30$ & 9.1 & \pm 2.2 & $9.1 \pm$ & \pm & 2.1 \\
\hline \multirow[t]{3}{*}{ Alphen } & $<16$ & 771 & \pm 73 & 57.7 & \pm 0.0 & $65.2=$ & \pm & 0.0 \\
\hline & $16-63$ & 306 & \pm 161 & 18.1 & \pm 3.7 & $11.5=$ & \pm & 3.0 \\
\hline & $>63$ & 179 & $\pm \quad 20$ & 6.2 & $\pm \quad 1.1$ & $5.8=$ & \pm & 0.9 \\
\hline
\end{tabular}

from small to large. The parameter set at the left-hand side of the graph (run number 1) yields the best fit. Figure $8 \mathrm{~b}-\mathrm{d}$ shows the graphs of the three partial radioactivities $S_{f, K}, S_{m, K}$, and $S_{C, K}$ separately, again with the runs arranged according to increasing values of $J_{K}(S)$. The values of $J_{K}(S)$ increase rapidly

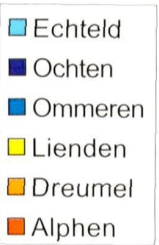

Fig. 6. Radiometric fingerprints of ${ }^{40} \mathrm{~K},{ }^{238} \mathrm{U}$ and ${ }^{232} \mathrm{Th}$, with 1 standard deviation uncertainty range (blue bars: Rhine; yellow-red bars: Meuse). 

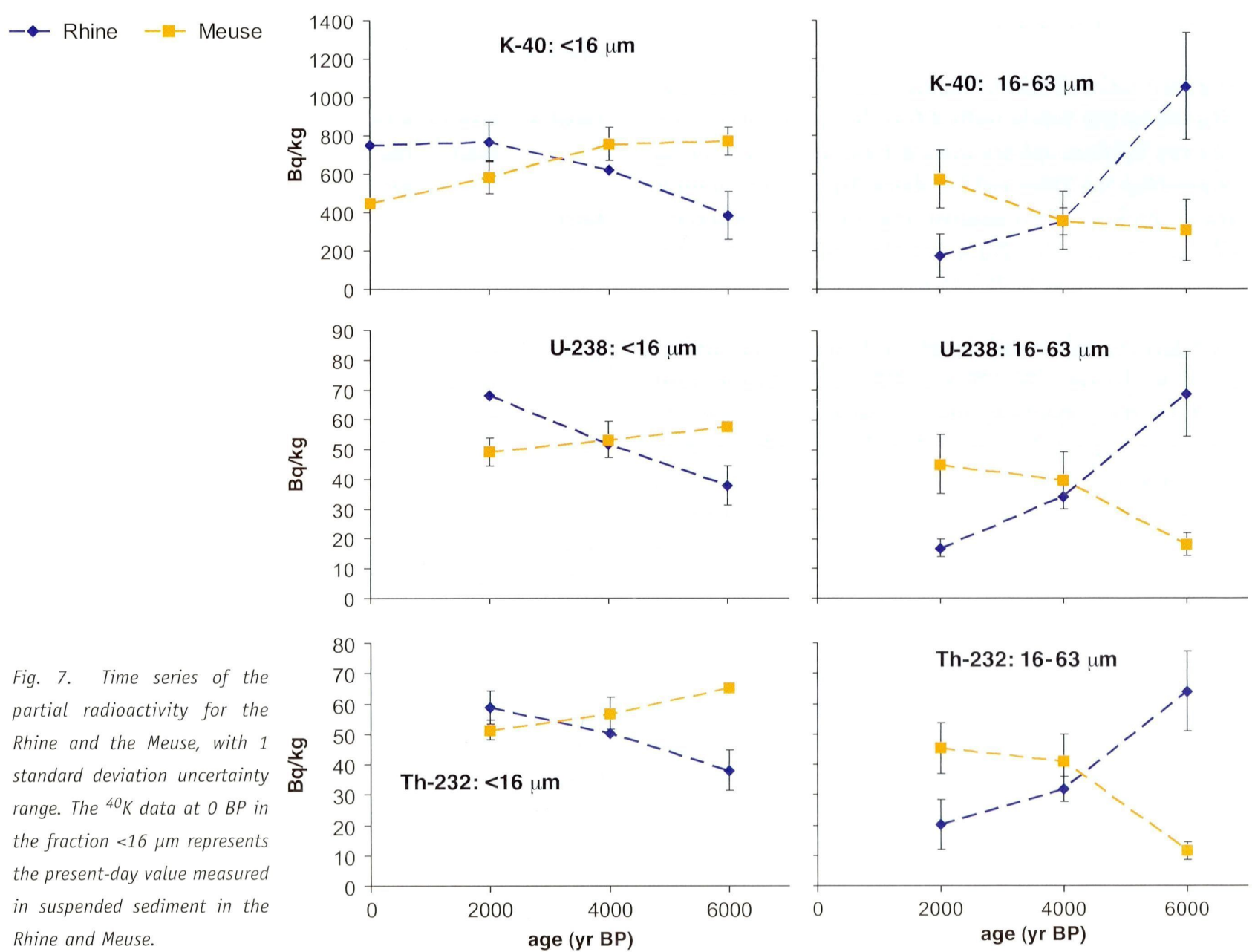

when the partial activities deviate more from their best value. With a tolerance in $J_{K}(S)$ in the order of about $50 \%$, the best 10 values for $S_{f, K}, S_{m, K}$, and $S_{c, K}$ might be considered to represent the uncertainty. The resulting standard deviations for these best sets are added in Table 2. The standard deviations are also indicated in Fig. 7. The analyses demonstrate that the uncertainties in the fingerprints are small when compared to the differences between the sites. The largest uncertainty was found in the partial radioactivity for the silt-sized (16-63 $\mu \mathrm{m})$ material. Still, the results indicate that the differences between the sites are larger than the uncertainties in the fingerprints.

To determine the effect of the choice of the fraction boundaries on the fingerprints, partial radioactivities were also determined using different grain size intervals for the three fractions. Ideally, this would be done for a great number of fraction boundaries to identify those grain size fractions that show the largest radiometric differences between the deposits. For this purpose, we attempted to define the fraction boundaries such that the different peaks in the grain size histograms of the samples of the same lithological classes fell in the same grain size fraction. This resulted in the boundaries of $32 \mu \mathrm{m}$ between the fine and medium fraction and $250 \mu \mathrm{m}$ between the medium and coarse fraction. The partial radioactivity of these fractions is shown in Fig. 9. The difference in partial radioactivity is much smaller now, so the samples cannot be distinguished with these partial radioactivities. A trend with the age of the deposits also cannot be recognised any longer. It is striking that now by far the highest radioactivity is measured in the finest grain size fraction, especially for the elements ${ }^{238} \mathrm{U}$ and ${ }^{232} \mathrm{Th}$. Apparently, the differences in radiometry occur within the finer (clay and silt) fractions. By shifting the upper boundary of the finer fraction to a larger grain size, the radiometric differences all lie within the finest fraction, making the resulting average values all similar. Consequently, the differences between the samples from Rhine and Meuse, and between samples from different age has become unrecognisable.

\section{Geochemical fingerprints}

To determine whether the signal in the partial radioactivity is a unique signal or only a reflection of the geochemistry, the inverse matrix method was also used to calculate 'geochemical fingerprints' of the elements that were analysed. This analysis was carried out with the original fraction boundaries of $16 \mu \mathrm{m}$ and $63 \mu \mathrm{m}$. The fingerprints of most of the elements show no 

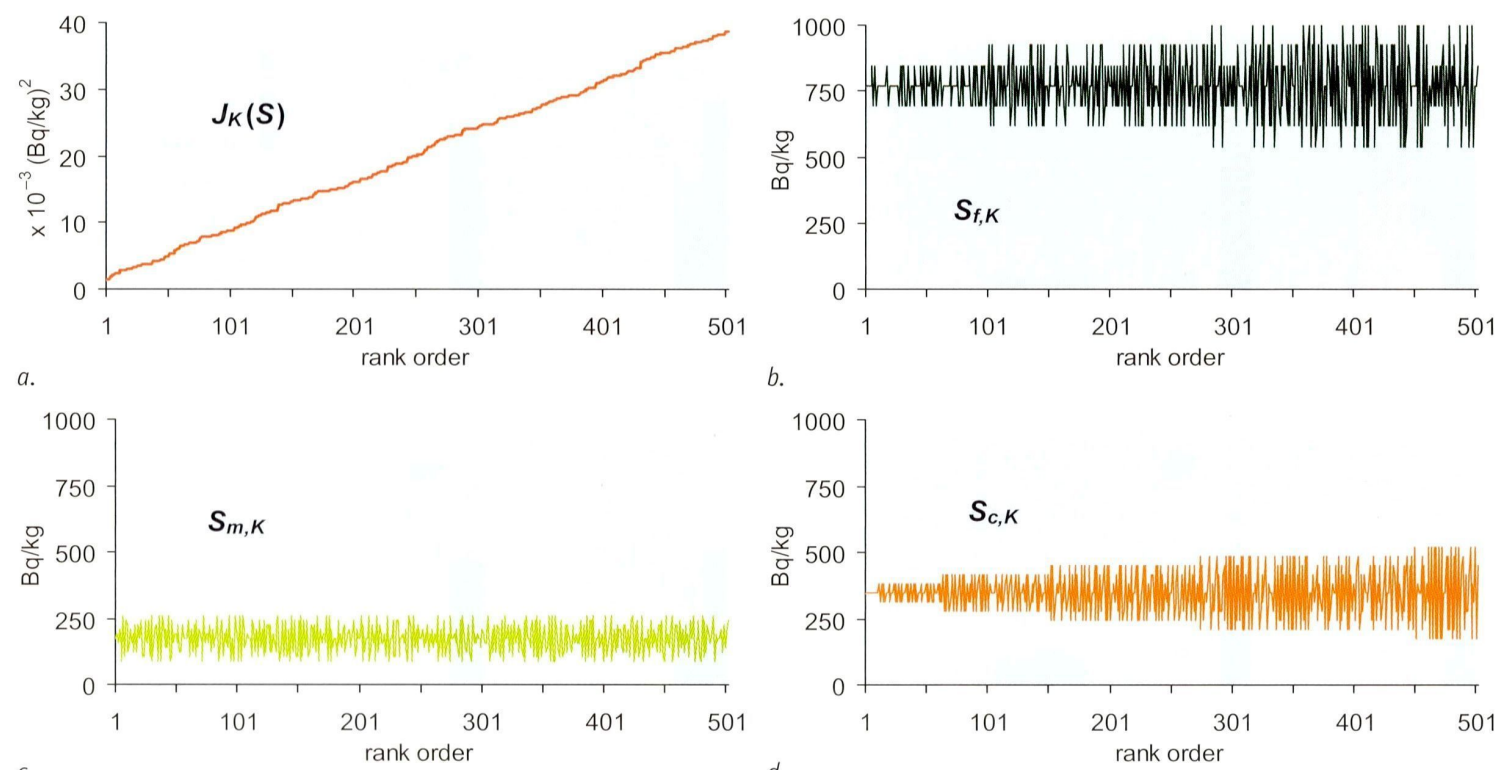

c.

d.

Fig. 8. Evaluation criterion $J_{K}(S)$ for the calculated radioactivity of ${ }^{40} \mathrm{~K}$ of the Echteld data from the partial radioactivities, for the 500 lowest values of $J_{K}(S)(a)$; values of the $40 K$ partial radioactivity for the fine fraction (b), the silt-sized fraction (c) and the sand fraction (d), arranged according to increasing values of $J_{K}(S)$ as in $A$.

comparison with the radiometric fingerprints. Some of them ( $\mathrm{Ca} 0, \mathrm{MgO}, \mathrm{Na}_{2} \mathrm{O}, \mathrm{Cu}, \mathrm{Zn}$ and $\mathrm{Sr}$ ) show only a difference between the Rhine and the Meuse and others like $\mathrm{Ni}, \mathrm{Ba}, \mathrm{Rb}, \mathrm{Nb}, \mathrm{Y}$ and La show only a trend with the age of the deposit, which is comparable for the Rhine and the Meuse. The four elements with the highest correlation with ${ }^{40} \mathrm{~K},{ }^{238} \mathrm{U}$ and ${ }^{232} \mathrm{Th}$ are $\mathrm{K}_{2} 0$, $\mathrm{TiO}_{2}, \mathrm{Rb}$ and $\mathrm{Nb}$. The geochemical fingerprints of these elements are shown in Fig. 10. The concentration of $\mathrm{K}_{2} \mathrm{O}$ and $\mathrm{TiO}_{2}$ that correlate the most to respective ${ }^{40} \mathrm{~K}$ and ${ }^{238} \mathrm{U}$, show no clear relation with the age of the deposits. The elements $\mathrm{Rb}$ and $\mathrm{Nb}$ have a stronger relation to the age of the deposits, but only the fingerprint of niobium shows the same information about the different deposits as the radiometric fingerprints.

\section{Interpretation and discussion}

The investigated deposits of the Rhine and the Meuse differ in natural radioactivity of ${ }^{40} \mathrm{~K},{ }^{238} \mathrm{U}$ and ${ }^{232} \mathrm{Th}$. The activity in
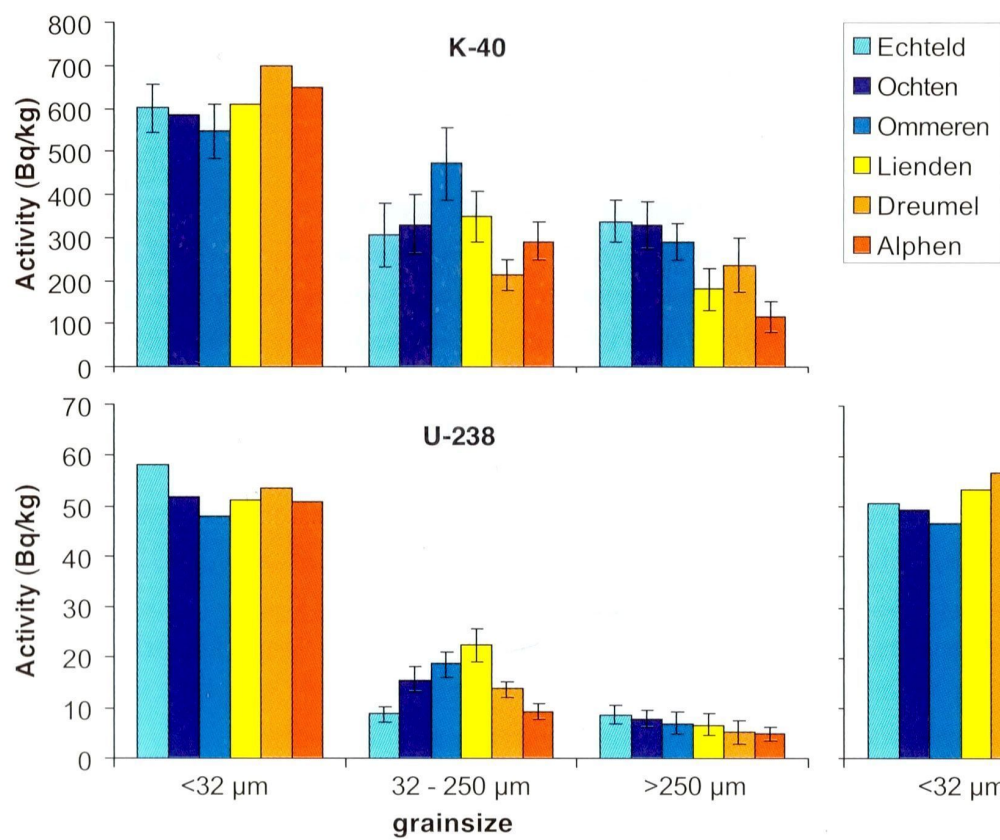

$\square$ Alphen

Fig. 9. Radiometric fingerprints for the grain size $<32 \mu \mathrm{m}, 32-250 \mu \mathrm{m}$ and $>250 \mu \mathrm{m}$, with 1 standard deviation uncertainty range (blue bars: Rhine; yellow-red bars: Meuse). 

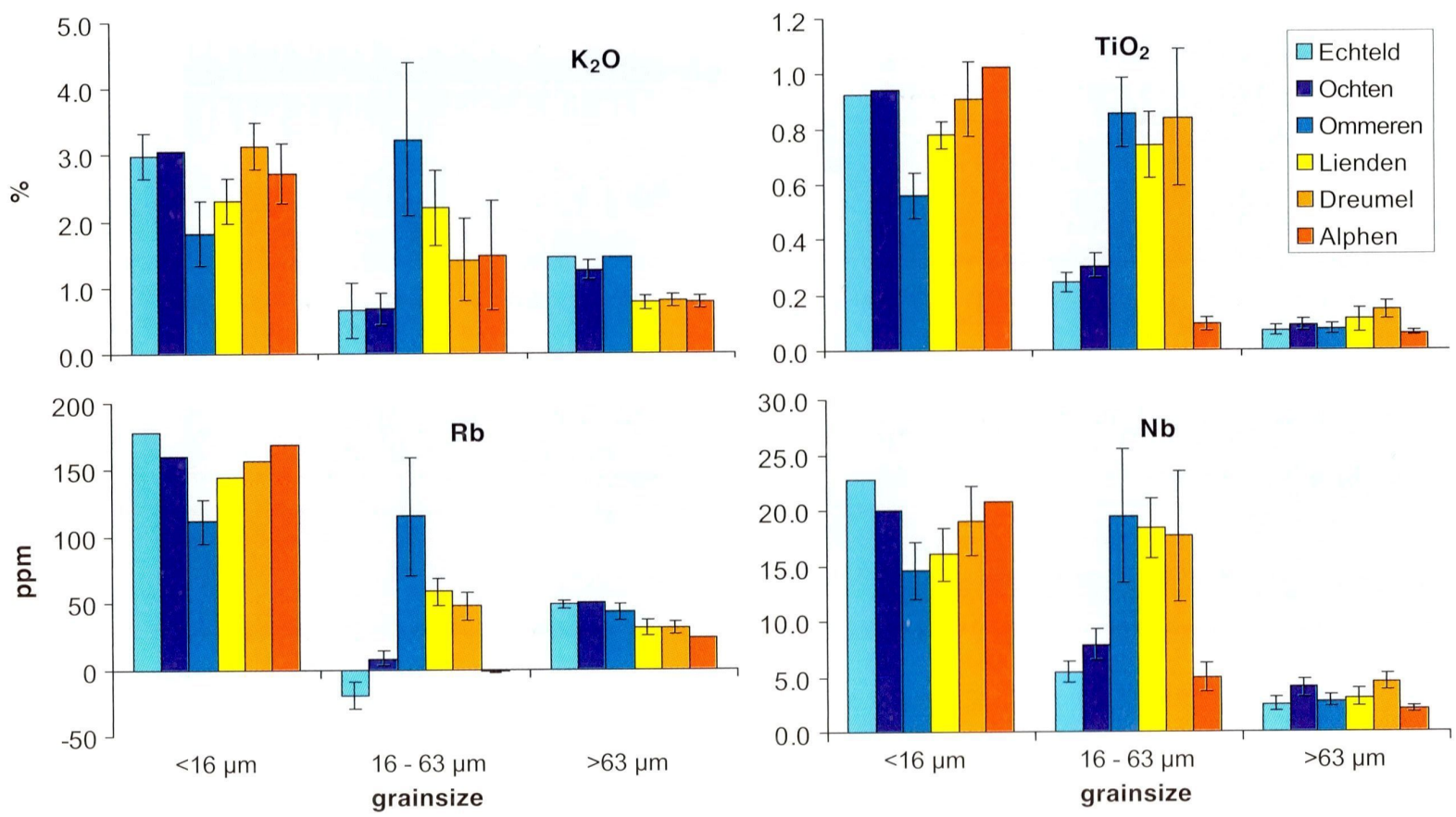

Fig. 10. Geochemical fingerprints of the elements $\mathrm{K}_{2} \mathrm{O}, \mathrm{TiO}_{2}, \mathrm{Rb}$ and $\mathrm{Nb}$ (blue bars: Rhine; yellowred bars: Meuse), with 1 standard deviation uncertainty range.

the sediment is primarily determined by the grain size of the sediment, as shown previously by Venema et al. (1998). Similar effects of particle size on sediment properties were found by He \& Walling (1996) in the adsorption of ${ }^{137} \mathrm{Cs}$ and unsupported ${ }^{210} \mathrm{~Pb}$ by mineral soils and sediment, and by Thorne \& Nickless (1981) and Middelkoop (2000) in studies of heavy metal concentrations in inter-tidal and floodplain sediments. Therefore, it is important to determine the partial radioactivities for the clay $(<16 \mu \mathrm{m})$ and silt $(16-63 \mu \mathrm{m})$ fractions, because the radiometric difference between the Rhine and the Meuse appears in these fractions. The radiometric signal in these grain size fractions in the Rhine sediment is opposite from the Meuse sediment. These differences are counterbalanced in the total radioactivity that, consequently, does not show a difference between Rhine and Meuse sediment. When partial radioactivities of the grain size fractions are considered, the radiometric signal seems to be determined by the source area (Rhine or Meuse) and the age of the deposits as well. During the Holocene, the radiometric differences between the Rhine and the Meuse have reversed. In the clay fraction, for example, the activity of ${ }^{40} \mathrm{~K}$ of deposits older than $4000{ }^{14} \mathrm{C}$ yr BP is higher in the Meuse deposits, while the ${ }^{40} \mathrm{~K}$ activity in deposits younger than $4000{ }^{14} \mathrm{C}$ yr BP is higher in the Rhine deposits. Therefore, the method cannot be used for all Holocene deposits, because around $4000{ }^{14} \mathrm{C}$ yr BP the difference between the Rhine and the Meuse is too small. Thus, to distinguish the deposits of the Rhine and the Meuse, both the grain size composition and the age of the deposits have to be known.

The radiometric fingerprints appeared sensitive for changes in the boundaries of the grain size fractions for which the partial fingerprints were determined. For this research the fraction boundaries of $16 \mu \mathrm{m}$ and $63 \mu \mathrm{m}$ were used, but these fractions are possibly not the best to determine the radiometric differences between the deposits of the Rhine and the Meuse. However, using grain size fraction boundaries derived from the sample grain size histograms, reflecting grain size classes that are the result of natural sorting by the river during sediment transport, did not yield clear radiometric fingerprints. Apparently, the opposite trends in the partial radioactivity that characterise the fingerprints occur in grain size fractions that are independent of the sorting of the sediment and independent of the way of transport. Determination of the optimal grain size boundaries for radiometric fingerprinting should therefore be further explored.

Investigating the cause of the radiometric differences was beyond the scope of this study. Nevertheless, it is likely that the difference between the Rhine and the Meuse is caused by differences in mineralogical composition of the drainage area of the two rivers. The changes in radioactivity during the Holocene can be caused by changes in land use or erosion under the influence of human activities or varying weathering intensities under climate change (cf. Tebbens, 1999). However, over time the radioactivity might have changed as well, due to continued weathering in the basin area. Remarkably, the radiometric differences between the samples seem more distinct than the geochemical differences.

In this study we have found radiometric differences between Rhine and Meuse sediments from three different ages. However, the available data set did not allow determination of variations in the radiometric signal within the same channel belt, neither 
could we evaluate whether the observed trends in radiometric signal over time are consistent. This would require additional sampling from a single channel belt as well as sampling other channel belts from different ages.

\section{Application}

The radiometric differences between the Rhine and the Meuse, that appear mainly in the silt and clay-sized fractions, enable to determine whether flood basin deposits in the delta origin from the Rhine or Meuse river, which previously has not been possible. Assuming that the radiometric fingerprints derived in the present study are consistent and valid for the RhineMeuse delta, they can be applied to estimate the relative contribution of Rhine and Meuse sediment in a floodbasin deposit of unknown origin by solving the following equation:

$$
C_{\text {Rhine }} \cdot\left|F_{s}\right| \cdot\left|S_{\text {Rhine }, t}\right|+C_{\text {Meuse }} \cdot\left|F_{s}\right| \cdot\left|S_{\text {Meuse }, t}\right|=\left|A_{s}\right|
$$

With: $\left|F_{S}\right| \quad=$ measured sample grain size matrix

$\left|S_{\text {Rhine, }}\right|=$ matrix of partial radioactivities (fingerprint) for Rhine sediment, for age $t$

$\left|S_{\text {Meuse, }}\right|=$ matrix of partial radioactivities (fingerprint) for Meuse sediment, for age $t$

$\left|A_{s}\right| \quad=$ matrix of total radioactivity measured in sample

$C_{\text {Rhine }}=$ fraction of sediment deposited by the Rhine

$C_{\text {Meuse }}=$ fraction of sediment deposited by the Meuse

t $\quad=$ estimated sample age

The total radioactivities of ${ }^{40} \mathrm{~K},{ }^{238} \mathrm{U}$ and ${ }^{232} \mathrm{Th}$ and the grain size matrix of the sample must be determined in the laboratory. The fingerprints are derived from the present research, and depend on the age of the deposit (Table 2). Thus, the age of the samples has to be known to apply the correct fingerprints. The grain size fraction boundaries to which these fingerprints apply are $16 \mu \mathrm{m}$ and $63 \mu \mathrm{m}$.

\section{Conclusions}

This research showed that the deposits of the Rhine and the Meuse in the Netherlands differ in the radioactivity of the isotopes ${ }^{40} \mathrm{~K},{ }^{238} \mathrm{U}$ and ${ }^{232} \mathrm{Th}$ and indicates that these radiometric characteristics can be used to distinguish the deposits of the Rhine and the Meuse in the Rhine-Meuse delta. The effect of the grain size on the radiometry is dominant over differences with age and source area. To reduce this effect, radiometric fingerprints must be based on the partial radioactivities of the grain size fractions clay $(<16 \mu \mathrm{m})$, silt $(16-63 \mu \mathrm{m})$ and sand $(>63 \mu \mathrm{m})$. These radiometric fingerprints also seem to change with the age of the deposits. Remarkably, trends in partial radioactivities over time of the Rhine deposits are opposite to those of the Meuse. For both rivers, these trends are opposite in the clay and silt fraction. In the sand fraction no differences appeared at all. The radiometric differences between the samples seem more distinct than the geochemical differences, which seems to make the radioactivity more suitable to distinguish the deposits of the Rhine and the Meuse in comparison with the geochemistry.

This first assessment of radiometric fingerprinting of Rhine and Meuse sediments suggested that it is possible indeed to distinguish the deposits of the Rhine and the Meuse within the floodplain, and to derive the contribution of Rhine and Meuse sediment in a deposit of unknown origin. Yet, this method requires further testing. Issues that should be addressed in a follow-up study might include further evaluation of the natural variability of the fingerprint among deposits from the same age and source, assessing combined chemicalradiometric fingerprints, relating fingerprints to source areas within the Rhine and Meuse basins, and applying the fingerprint to a long sediment core from the delta with a mixture of Rhine and Meuse floodbasin sediments to identify the relative contributions from both sources. When such tests are successful, radiometric fingerprinting may enable a more detailed palaeogeographic reconstruction of the development of the Rhine-Meuse delta in the Netherlands and - potentially - an estimate of the individual contribution of both rivers in the development of the delta during the Holocene.

\section{References}

Berendsen, H.J.A., 1996. Fysisch-geografisch onderzoek; thema's en methoden. Koninklijke Van Gorcum, (Assen): 214 pp.

Berendsen, H.J.A. \& Stouthamer, E., 2001. Palaeogeographic development of the Rhine-Meuse delta, the Netherlands. Koninklijke Van Gorcum (Assen): $268 \mathrm{pp}$.

Cohen, K.M., 2003. Differential subsidence within a coastal prism; Late GlacialHolocene tectonics in the Rhine-Meuse delta, the Netherlands. PhD Thesis. Netherlands Geographical Studies 316: 176 pp.

Collins, A.L., Walling, D.E. \& Leeks, G.J.L., 1997. Fingerprinting the origin of fluvial suspended sediment in larger river basins: combining assessment of spatial provenance and source type. Geografiska Annaler (A) 79: 239-254.

Collins, A.L. \& Walling, D.E., 2002. Selecting fingerprint properties for discriminating potential suspended sediment sources in river basins. Journal of Hydrology 261: 218-244.

Collins, A.L. \& Walling, D.E., 2004. Documenting catchment suspended sediment sources: problems, approaches and prospects. Progress in Physical Geography 28, 159-196.

De Meijer, R.J., 1998. Heavy minerals: from 'Edelstein' to Einstein. Journal of Geochemical Exploration 62: 81-103.

De Meijer, R.J. \& Donoghue, J.F., 1995. Radiometric fingerprinting of sediments on the Dutch, German and Danish coasts. Quaternary International 26: 43-47.

De Meijer, R.J., Lesscher, H.M.E., Schuiling, R.D. \& Elburg, M.E., 1990. Estimate of the heavy mineral content in sand and its provenance by radiometric methods. Nuclear Geophysics 4: 455-460. 
Garrad, P.N. \& Hey, R.D., 1989. Sources of suspended and deposited sediment in a broadland river. Earth Surface Processes and Landforms 14: 41-62.

Gingele, F.X. \& De Deckker, P., 2003. Fingerprinting Australia's rivers using clays and the application for the marine record of rapid climate change. In: Roach, I.C. (ed.): Advances in regolith, CRC LEME: 140-143.

Hakstege, A.L., Kroonenberg, S.B. \& Van Wijck, H., 1993. Geochemistry of Holocene clays of the Rhine and Meuse in the central-eastern Netherlands, Geologie en Mijnbouw 71: 301-315.

He, Q. \& Walling, D.E., 1996. Interpreting particle size effects in the adsorption of $137 \mathrm{Cs}$ and unsupported $210 \mathrm{~Pb}$ by mineral soils and sediment. Journal of Environmental Radioactivity 30: 117-137.

Thorne, L. \& Nickless, G., 1981. The relation between heavy metals and particle size fractions within the Severn estuary (UK) inter-tidal sediments. The Science of the Total Environment 19: 207-213.

Johnson, A.G. \& Kelley, J.T., 1984. Temporal, spatial and textural variations in the mineralogy of the Mississippi River suspended sediment. Journal of Sedimentary Petrology 54: 67-72.

Lewin, J. \& Wolfenden, P.J., 1978. The assessment of sediment sources: a field experiment. Earth Surface Processes and Landforms 3: 171-178.

Loughran, R.J., Campbell, B.L. \& Elliott, G.L., 1982. The identification and quantification of sediment sources using 137Cs. In: Walling, D.E. (ed): Recent developments in the explanation and prediction of erosion and sediment yield, IAHS publication no. 137 IAHS Press (Wallingford): 361-369.

Middelkoop, H., 2000. Heavy-metal pollution of the river Rhine and Meuse floodplains in the Netherlands. Netherlands Journal of Geosciences 79: 411-428.

Motha, J.A., Wallbrink, P.J., Hairsine, P.B. \& Grayson, R.B., 2004. Unsealed roads as suspended sediment sources in an agricultural catchment in southeastern Australia. Journal of Hydrology 286: 1-18.

Oldfield, F., Rummery, T.A., Thompson, R. \& Walling, D.E., 1979. Identification of suspended sediment sources by means of magnetic measurements: some preliminary results. Water Resources Research 15: 211-218.

$N E N, 2000$. Bepaling van de activiteit van gammastraling uitzendende nucliden in een telmonster met behulp van halfgeleider-gammaspectrometrie, Nederlandse norm, NEN5623

Peart, M.R. \& Walling, D.E., 1986. Fingerprinting sediment source: the example of a drainage basin in Devon, UK. In: Hadley, R.F. (ed): Drainage basin sediment delivery, IAHS publication no. 159. IAHS Press (Wallingford): 41-55.

Phillips, J.D., 1992. Delivery of upper-basin sediment to the Lower Neuse River, North Carolina, USA. Earth Surface Processes and Landforms 17: 699-709.

Porto, P., Walling, D.E., Tamburino, V. \& Callegari, G., 2003. Relating ceasium-137 and soil loss from cultivated land. Catena 53: 303-326.

Schoeneberger, P.J., Wysocki, D.A., Benham, E.C. \& Broderson, W.D. (eds), 2002. Field book for describing and sampling soils, Version 2. Natural Resources Conservation Service, National Soil Survey Center, Lincoln, NE.

Slattery, M.C., Walden, J. \& Burt, T.P., 2000. Use of mineral magnetic measurements to fingerprint suspended sediment sources: results from a linear mixing model. In: Foster, I.D.L. (ed.): Tracers in Geomorphology. John Wiley and Sons Ltd. (Chichester): 309-322.

Stouthamer, E., 2001. Holocene avulsions in the Rhine-Meuse delta, the Netherlands. PhD Thesis. Netherlands Geographical Studies 283: 211 pp.

Tebbens, L.A., 1999. Late Quaternary evolution of the Meuse fluvial system and its sediment composition; A reconstruction based on bulk sample geochemistry and forward modelling. PhD Thesis, Wageningen University: $157 \mathrm{pp}$.
Van Wijngaarden, M., Van den Berg, G.A. \& Fioole, A., 2000. Bodem in beeld. RIZA report 2000.005. RIZA (Dordrecht): 28 pp.

Van Wijngaarden, M., Venema, L.B., De Meijer, R.J., Zwolsman, J.J.G., Van Os, B. \& Gieske, J.M.J., 2002a. Radiometric sand-mud characterisation in the Rhine-Meuse estuary; Part A. Fingerprinting. Geomorphology 43: 87-101.

Van Wijngaarden, M., Venema, L.B. \& De Meijer, R.J., 2002b. Radiometric sand-mud characterisation in the Rhine-Meuse estuary; Part B. In situ mapping. Geomorphology 43: 103-116.

Venema, L.B., Ten Have, R., De Meijer, R.J., Van Os, B., Gieske, J.M.J. \& Zwanenbug-Nederlof, H.P., 1998. Radiometric survey of 'Hollandsch Diep' Part I: Feasibility study and radiometric and geochemical characterization. KVI and TNO-NITG internal report Z-70: $87 \mathrm{pp}$.

Venema, L.B., Ten Have, R., De Meijer, R.J., Van Os, B., Gieske, J.M.J. \& Zwanenbug-Nederlof, H.P., 1999. Radiometric survey of 'Hollandsch Diep' Part II: Mud-sand mapping. KVI and TNO-NITG internal report Z-78: 65 pp.

Walden, J., Slattery, M.C. \& Burt, T.P., 1997. Use of mineral magnetic measurements to fingerprint suspended sediment sources: approaches and techniques for data analysis. Journal of Hydrology 202: 353-372.

Walling, D.E. \& Woodward, J.C., 1992. Use of radiometric fingerprints to derive information on suspended sediment sources. In: Bogen, J., Walling, D.E. \& Day, T., (eds): Erosion and sediment transport monitoring programmes in River Basins. IAHS Publication 210: 153-164. 